\title{
OBESITEIT
}

\section{'N TEORETIESE VERKENNING}

\section{LANDA OELOFSE}

\section{Lektise/Psigiatriese verpleegkundige,}

\section{Departement Verpleegkunde, Potchefstroomse Universiteit vir CHO.}

\section{INLEIDING}

Obesiteit word vandag as 'n wesenlike gesondheidsprobleem beskou, omdat die fisiese gesondheid sowel as die psigologiese funksionering van 'n individu daardeur geraak word. In die behandeling hiervan word massaverminderingsprogramme beklemtoon, terwyl die psigologiese aspekte negeer word.

Hierby word vanuit die omgewing sterk druk op verslanking en slank wees geplaas, veral by die vrou. Hierdie negering en druk lei daartoe dat die obese vrou nie in staat is om haar probleem alleen te hanteer nie. Om dit op te los moet dus gedink word aan groter klem op die psigologiese aspekte van obesiteit in die behandeling daarvan.

\section{OMSKRYWING VAN OBESITEIT}

Volgens Sloan (1970:374) en Gouws, Louw. Meyer en Plug (1979:203) kan obesiteit as die neerlegging van 'n groot hoeveelheid vet in die liggaam gedefinieer word.

White en Schroeder (1981: 550) maak 'n onderskeid tussen obesiteit en oormassa. Hiervolgens word in individu as oormassa beskou wanneer hy of sy 10 persent bo die gewensde maksimum massa vir die betrokke lengte- en geslagstandaarde is. Indien die individu egter 20 persent of meer oormassa is, is hy obees.

Die beskrywing van Vlok (1974:149) word as die aanvaarbare riglyn ten opsigte van die begrip obesiteit gebruik. naamlik 'n verhoging van die individu se liggaamsvet. waar die liggaamsmassa met meer as $20 \%$ bo die gemiddelde massa van individue van dieselfde ouderdom, geslag, lengte en ras styg.

\section{SUMMARY}

In a theoretical discussion on obesity the author shows that it is a complex condition, particularly as psychological factors play a significant role in its etiology.

Various treatments exist including diet therapy, physical activity, medication, surgery, individual phychotherapy, behaviour therapy. It seems however that a group psychotherapeutic approach to treatment has the best prognostic value. Whatever method of treatment is used, however, physical as well as psychological aspects should be attended to.

\section{INSIDENSIE VAN OBESITEIT}

Alhoewel obesiteit by enige geslag en op enige ouderdom kan voorkom is dit meer algemeen by vroue en wel na puberteit. Meer spesifiek kom obesiteit meer algemeen na swangerskap en tydens die menopouse voor (Tymkiw 1978:42).

\section{DIAGNOSE VAN OBESITEIT}

'n Verskeidenheid metodes (sommige meer wetenskaplik as ander) word gebruik om oormassa te bepaal:

- die spieëltoets. Volgens Mayer $(1968: 29)$ is in persoon wat in in spieël kyk en vet lyk, wel vet.

- die knyptoets. Indien ' $\mathrm{n}$ persoon sy vel knyp en die bult is breër as 2.5 $\mathrm{cm}$. dui dit op oormatige liggaamsvet.

- die liniaal toets. Hierdie toets meet die helling van die abdomen wanneer 'n persoon op sy rug lê. Indien die persoon nie obees is nie is die oppervlakte van die abdomen tussen die ribbes en die simfeses pubis plat of effens konkaaf (Mayer 1968:29).

- Kalliper. Hier word die relatiewe dikte van die subkutane vetlae gemeet. Die metode is eintlik 'n verfyning van die knypmetode omdat foutiewe meting as gevolg van in oormaat vloeistof of gesonde spierweefsel uitgeskakel word.

- ander metodes wat gebruik word is die gordellyntoets, hidrometrie, ultrasoniese meting van subkutane vet en sagte weefsel X-strale (Mayer 1968:30-31 en Sloan 1970:379).

- die metode wat moontlik vandag die meeste gebruik word is massatabelle. Die Departement van Gesondheid en Welsyn het sulke standaardtabelle vir verspreiding opgestel.

\section{ETIOLOGIE VAN OBESITEIT}

Die verskynsel van obesiteit het raakpunte in verskeie dissiplines soos die medisyne, die psigologie en die verpleegkunde. Tog word die probleme in verband daarmee in al die dissiplines baie oppervlakkig benader

Vlok (1974:149) noem slegs vier oorsaaklike faktore van obesiteit. naamlik ooreet. metaboliese of hormonale versteurings en te min oefening.

Tymkiw (1978:43) is van mening dat obesiteit selde aangetref word in persone wat 'n aktiewe lewe lei. Verder sê hy dat obese ouers dikwels obese kinders het. wat toegeskryf word aan die model wat die ouers aan die kinders stel.

Wineman (1980:231-237) haal Schachter se stimilus-bindinghipotese aan, wat impliseer dat 'n obese persoon se eetgedrag beïnvloed word deur die opvallendheid van eksterne leidrade (bv. voedseladvertensies) eerder as interne oriëntasie (dit wil sê die fisiologiese behoeftes aan voedsel).

Bauer (soos in Rubin en Novak 1956:348) meen obesiteit is primêr 'n geneties-konstitusionele anomalie 
waarin ekstrinsieke invloede 'n sekondêre rol speel. In kontras met die meeste skrywers (soos aangehaal deur Bauer) wat verskeie vorms van obesiteit aan òf oordeel òf endokriene versteurings toeskryf, reduseer Bauer (in Rubin en Novak 1956:348) amper alle tipes obesiteit tot 'n algemene faktor, naamlik die eindresultaat van 'n genetiese anomalie van vetmetabolisme.

Volgens die Departement van Gesondheid (Bulletin 358 en 379) speel emosionele en omgewingsfaktore 'n groot rol as oorsaak van ooreet. Hiervolgens eet baie mense sonder om die fisiologiese behoeftes aan voedsel te ervaar of te bevredig. Hierdie gewoonte kan dikwels teruggevoer word na die vroeë kinderjare toe voedselinname met die ervaring van liefde en sekuriteitsgevoelens geassosieer is. Eetgewoontes van ander persone in die gesin en die omgewing, die beskikbaarheid van voedsel, die groot verskeidenheid en keurige verpakking daarvan, en 'n gebrek aan oefening, is dus belangrike omgewingsfaktore wat obesiteit in die hand werk.

Volgens Craddock (1973:60-61) lei die daaglikse spanningsvolle situasies veral in interpersoonlike verhoudinge - daartoe dat die hipersensitiewe persoon meer passief as aktief optree, wat tot ooreet aanleiding kan gee.

Kaplan en Sadock (1981:604) is van mening dat somatipes 'n groot rol in obesiteit speel, omdat die verskynsel by abolessente meisies selde onder ektomorfe voorkom. Obesiteit wat vroeg in die persoon se lewe ontstaan word gekenmerk deur 'n groter aantal en groter vetselle. Daarenteen volg obesiteit wat in die volwassenheid begin. uit die vermeerdering in die grootte van die vetselle. Derdens word genoem dat die vernietiging van die ventro-mediale hipotalamus obesiteit tot gevolg het.

\section{KLINIESE BEELD VAN OBESITEIT}

\section{Fisiese simptome}

Die fisiese simptome van obesiteit kan in die volgende vyf groepe verdeel word (Rubin en Novak 1956:348):

- Ruben- of gordeltipe. Akkumulasie van vet is hoofsaaklik in die heupe, dye, laer deel van die abdomen, die boude en die rug gelokaliseer.

- Trogantriese tipe. Die vetweefsel is in die troganter area gelokaliseer.

- Inferiortipe. Die vetneerlegging is by die laer ekstremiteite, vanaf die heupe tot by die enkels.

- Superiortipe. Akkumulasie van vet is in die rug. arms, bene, borste, nek en gesig.

- Steatopigia. Dit is 'n abnormale, soms enorme, neerlegging van vet in die area van die boude. Dit vind plaas as 'n genetiese eienskap in sekere rasse, soos die Boesmans en Hottentotte.

Siektes wat meer algemeen by obese persone voorkom, sluit diabetes, koronêre hartvatsiektes, jig, kroniese brongitis, artritis en hipertensie in. Hierdie toestande kom kwantitatief sowel as kwalitatief in 'n groter mate by obese persone voor (Sloan 1970:374-379, Vlok 1974:149).

\section{Psigiese simptome}

By die meeste obese persone is daar geen enkele duidelik waarneembare psigologiese simptoom nie.

Volgens Wineman (1980:231-237) kan obesiteit reeds in die kinderjare ontstaan indien die kind met eet as beloning gekondisioneer word. Hierdie vroeë aanvang van obesiteit lei tot die vorming van 'n negatiewe liggaamsbeeld.

Deur 'n liggaamsbeheptheid en gepaardgaande neurotiese persoonlikheidsimptome, word die negatiewe liggaamsbeeld versterk (Wineman 1980:231-237). In die literatuur (Sontag in Hurlock 1964:126, Gerardt, Robbertse, Laubscher en du Plessis 1974:2507-2508, Nel 1975:81, Werkman en Greenberg 1980:231-237) word die volgende moontlike simptome genoem:

- onvolwassenheid,

- hipersensitiwiteit,

- angstigheid,

- gevoelens van ontoereikendheid,

- gevoelens van fisiese gebrekkigheid,

- geneigdheid tot depressie.

- hipokondrie,

— rigiditeit,

- narcisme,

- agterdogtigheid.

- valse sekuriteitsgevoel en

- skuldgevoelens omtrent eetgewoontes.

'n Ander aspek wat tot 'n negatiewe (Wineman 1980:231-237) en onrealistiese (Gerardt et al 1974:2507-2508) liggaamsbeeld lei, is neerhalende reaksie en terugvoering van ander op 'n vroeë leeftyd. Die obese persoon is ook dikwels aan negatiewe en selfs afkeurende terugvoering van ander onderwerp (Lewis 1078:22-24).
Die meerderheid obese kinders word selfs voordat hulle skooltoe gaan bewus van hoe andere oor hul oormassa voel. Hulle voel ' $n$ bejammering van volwassenes aan en dat maats voel dat hul massa inmeng met hul vermoë om aan aktiewe spel deel te neem. Hierdie blootstelling aan afkeuring en sosiale isolasie het tot gevolg dat hulle weerhou word van geleenthede om effektiewe sosiale interaksies aan te leer. Die gevolg is dat die obese persoon nie genoegsaam toegerus is om die eise van die volwasse lewe te hanteer nie (Hurlock 1964:125 en 126).

Die vorming van die swak liggaamsbeeld by die obese persoon word verder aangehelp deur die Westerse samelewing wat oormassa as lelik en onfatsoenlik beskou. Die obese persoon leef dus onder die wolk van 'n intimiderende sosiale omgewing, waarin hy volgens sy obesiteit, en nie volgens sy potensiaal geëvalueer word nie. Hierdie negatiewe omgewingsfaktore lei tot 'n onrealistiese liggaamsbeeld (Gerhardt et al 1974:2507-2508), en 'n negatiewe, verwarde selfkonsep ontstaan ( Nel 1975:81) omdat die persoon nie 'n georganiseerde, gedifferensieerde innerlike self kan ontwikkel nie (Nathan in Wineman 1980:236).

\section{TERAPIE VIR OBESITEIT}

Daar bestaan geen eenvoudige of enkelvoudige terapie vir obesiteit nie. Behandeling wissel van dieetkontrole tot tablette, steungroepe en drastiese chirurgiese prosedures (White en Schroeder 1981:553).

'n Hooffaktor in effektiewe massavermindering is hoë motivering. met ander woorde dat die slagoffer van obesiteit werklik die begeerte om slank te word, en te bly, moet hê (Mayer 1968:153).

Verskeie terapeutiese modelle in die behandeling van obesiteit kan gedefinieer word.

\section{Dieetterapie}

Die basis van massavermindering is om 'n kilojoule-tekort daar te stel deur die inname minder as die verbruik te maak (Baird en Howard 1969:92, De Lamater 1981:24; Kaplan en Sadock 1981:605). Die dieet moet egter kragtiger in kilojoule, voedsaam, sosiaal aanvaarbaar en ekonomies wees en oor 'n lang tydperk gevolg word. 


\section{Algehele eetstaking}

Hierdie metode vir massavermindering moet onder toesig van 'n geneesheer plaasvind, omdat komplikasies soos aritmie, asidose, hipotensie en selfs die dood kan voorkom (Baird en Howard 1969:98; De Lamater 1981:24).

\section{Fisiese aktiwiteit}

Volgens Kaplan en Sadock (1981:606) is oefening as enigste metode vir massavermindering nie baie effektief nie. Craddock (1969:99) sê: An increase in the amount of regular exercise undertaken should be part of the weight reduction regime for every patient with no medical contra-indications.

\section{Medikasie}

Chemoterapie is nie ' $n$ baie suksesvolle metode vir massaverlies nie. Die mees algemene aptytdempende middels bevat Amfetamien of Fenfluramien wat albei gewoontevormend is (De Lamater 1981:24).

\section{Chirurgie}

Chirurgiese terapie word as 'n radikale terapie beskou weens die moontlike intra-operatiewe en ook langtermyn-risikos (De Lamater 1981:24).

\section{Individuele psigoterapie}

Die doel van individuele psigoterapie by obese persone is ingestel op die aanleer van nuwe houdinge en die verhoging van die individu se selfbeeld en egosterkte. Hierdie psigoterapie moet deur dieet en oefening aangevul word vir optimale resultate (De Lamater 1981:24).

\section{Hipnoterapie}

Hanley (in Craddock 1969:148) het in 1967 bevind dat hipnose 'n positiewe rol speel om pasiënte se houdings teenoor voedselinname te verander. Onvolwassenheid en ongemotiveerdheid lei egter nog tot 'n swak prognose.

\section{Gedragsterapie}

Foreyt (1977:1-5) identifiseer vyf terapeutiese tegnieke

- openlike afkeur,

- bedekte sensitisering.

- kondisionering,

— pasiënt-ondersteuning en

- selfkontrole.

Kaplan en Sadock (1981:607) meen dat gedragsmodifikasie geen oplossing vir die probleem van obesiteit bied nie, maar beskou gedragsmodifikasie terselfdertyd tog as die belangrikste nuwe ontwikkeling in die behandeling van obesiteit.

\section{Groepsterapie}

Vanweë die rasionaal dat die portuurgroep in die adolessente tydperk so 'n belangrike rol in sosialisering speel, het Longford (1981:556-559) obese adolessente meisies in kleingroepsverband behandel. Daar is op die totale persoon gefokus en nie net op die probleem van obesiteit nie. In sý ondersoek het Kahn (1978:254) bevind dat groepslede eerstens ' $n$ behoefte aan steun en motivering het voordat kontrole oor eetgewoontes aangeleer word. In die tweede plek noem hy dat homogeniteit tussen groepslede tot die sukses van die terapie bydra.

Na sý eksperimente het Strong (1975:459-461) tot die gevolgtrekking gekom dat die kleingroepsbenadering in die behandeling van obesiteit beter resultate as medikasie, chirurgie en oefening lewer.

\section{PROGNOSE VIR OBESITEIT}

Die prognose vir massavermindering is swak en die oorsaak van obesiteit neig na meedoënlose progressie (Kaplan en Sadock 1981:604).

Craddock (1969:140) beweer dat die prognose van obesiteit van die volgende faktore afhanklik is:

- volwassenes wat sedert hul kinderjare obees is toon moeiliker massaverlies,

- oormatige obesiteit is ' $n$ groter probleem as obesiteit van 'n laer graad,

- persone in die hoër inkomste groep vaar beter op massaverminderingsprogramme as andere.

- 'n mediese rede vir massavermindering verhoog die kans om met massavermindering sukses te behaal,

- mans is gewoonlik meer suksesvol as vroue,

- die getroude staat het 'n voordelige invloed op massavermindering, en

- persone wat kompulsief eet se prognose is swak.

\section{SAMEVATTING}

Uit die voorafgaande teoretiese bespreking blyk dit dat obesiteit kompleks is, veral daarin dat psigologiese faktore 'n beduidende rol in die etiologie daarvan speel. Dit blyk verder dat die groeppsigoterapeutiese benadering die hoogste prognostiese waarde toon.

In die literatuur (Egan 1977, Johnson 1981, Johnson en Johnson 1982) bestaan daar toenemende bewyse dat die kleingroepervaring met sy klem op selfontwikkeling. 'n hoogs bruikbare tegniek is vir die verkryging van insig in die self en die aflegging van die destruktiewe, neurotiese gedragspatrone waarmee obesiteit geassosieer word.

Uit die oorsig van die teorie kan die volgende aanbevelings gemaak word:

- in enige massaverminderingsprogram vir obese individue moet daar nie slegs aan voedselinname aandag geskenk word nie, maar ook aan die individu se psigologiese gesondheid,

- in terapie vir obesiteit moet die individu se totale funksionering (die Gestalt) betrek word, dit wil sê die fisiese sowel as die psigologiese. Wanneer albei aspekte terapeuties benader word, sal die obese persoon kan groei tot fisiese en psigologiese gesondheid, waarin albei aspekte geintegreerd en optimaal funksioneer.

\section{BIBLIOGRAFIE}

Baird. I M en Howard A N (1969). Obesiry-medical and scientific aspects. Edinburgh and London: E \& S Living stone Lid

Craddock. D (1973) Obesity and its management. London E \& S Livingstone Ltd

De Lamater. P V (1981) Obesiry - incidence, causes. pre vention and treatment. Occupational Health Nursing 29(9)

Departement van Gesondheid en Welsvn Bulletin 358 Bulletin 379 Pretoria.

Egan. G (1977) You and me. The skills of communicating and relating to others. California: Brooks/Cole Publishing

Foreyt. J.P. (1977) Preface. In Foreyt J P , red Behaviou ral Trearment of Obesity Oxford: Pergamon Press.

Gerhardt C: Robbertse J: Laubscher N.F.: Du Plessis J P (1974) Obesity - a psychological study. Suid Afrikaanse Mediese Tydskrif. 48(60): $2507-2508$. De sember 11.

Gouws L. A : Louw D A : Mever W F : Plug C (1979.) Psi gologie Woordeboek Johannesburg: McGraw-Hill.

Hurlock. E B (1964) Child deselopmens New York McGraw-Hill Book Company 4 th Ed.

Johnson. D W (1981) Reaching out - interpersonal effecriveness and self-actualization Englewood Cliffs Prentice-Hall. 2nd Ed.

Johnson D.W.: Johnson F P (1982) Joining togesher-group theory and group skills. Englewood Cliffs PrenticeHall.

Kahn A N (1978) Group Education for the Overweight American Journal of Nursing.

Kaplan H I : Sadock B J (1981) Modern synopsis of comprehensive textbook of psychiatry/lII. Baltimore Williams en Wilkins. 3rd Ed

Langford R W (1981) Teenagers and obesity. American Journal of Nursing.

Lewis, CW (1978) Body image and obesity Journal of Psychiasric Nursing and Mental Health Services.

Maver, J (1968) Overweight: causes. cost, and conurol London: Prentice-Hall.

Nel. M C P (1975) 'n Persoonlikheidsbeeld van adolessente meisies wat aan obesiteir ly. Potchefstroom. (SkripsieM A. Kliniese Sielkunde - P U vir C H O)

Rubin. I C; Novak. J. (1956) Integrased gynecology principles and practice volume II. London: McGraw-Hill.

Sloan, A W (1970) Obesity. Suid-Afrikaanse Tydskrif vir Wetenskap.

Tymkiw. G (1978) Obesity: a challenge for patient teaching. The Canadian Nurse.

Vlok. M E (1974) Manual of Basic Nursing Durban: Hayne and Gibson.

Werkman S L: Greenberg E S. Personality and interest pat. terns in obese adolescent girls. Psychosom. Med.

White J H : Schroeder M A (1981) Nursing Assesment American Journal of Nursing.

Wineman N M (1980) Obesity: locus of control. body image weight loss and age-at-onset. Nursing Research. 